\title{
On the Influence of Cold Work on the Oxidation Behavior of Some Austenitic Stainless Steels: High Temperature Oxidation
}

\author{
J. C. Langevoort, ${ }^{*}$ T. Fransen, ${ }^{*}$ and P. J. Gellings*
}

Received December 14, 1983

AISI 304, 314, 321, and Incoloy $800 H$ have been subjected to several pretreatments: polishing, milling, grinding, and cold drawing. In the temperature range $800-1400 \mathrm{~K}$, cold work improves the oxidation resistance of AISI 304 and 321 slightly, but has a relatively small negative effect on the oxidation resistance of AISI 314 and Incoloy $800 \mathrm{H}$. Milling results in an enlargement of the surface area with a factor 2.5 .

KEY WORDS: oxidation; stainless steel; cold work.

\section{INTRODUCTION}

The influence of the surface condition on the high temperature oxidation resistance of metals and alloys has been the subject of various investigations in the past. It is reported by Allan and Dean ${ }^{1}$ that cold work results in a better corrosion resistance in $\mathrm{CO}_{2}$ atmospheres at temperatures in the range $923-1023 \mathrm{~K}$. The temperature at which deformation is taking place is also assumed to play an important role. Cigada et al. ${ }^{2}$ showed that specimens of AISI 304 deformed at liquid nitrogen temperature were less resistant to SCC (stress corrosion cracking) than undeformed ones, whereas deformation at room temperature resulted in a better resistance to SCC. Leistikow ${ }^{3}$ found that cold work had a beneficial influence on the corrosion of Incoloy $800 \mathrm{H}$ below $1073 \mathrm{~K}$ and a negative effect above that temperature. Stevens ${ }^{4}$

\footnotetext{
* Twente University of Technology, Department of Chemical Technology, P.O. Box 217, 7500 AE Enschede, The Netherlands.
} 
observed that annealed specimens showed a better oxidation resistance than cold worked ones. Langevoort et al. ${ }^{5}$ reported an increase in oxidation resistance of AISI 304 and 321 in the temperature range $800-1000 \mathrm{~K}$, but a decrease in oxidation resistance of Incoloy $800 \mathrm{H}$ after cold work. Stokkers et $a l^{6}$ observed an increase in oxidation rate after ion bombardment of stainless steel AISI 314.

In this paper, the results of the oxidation measurements of several stainless steels are discussed in terms of defect structures introduced in the bulk by milling, rolling, grinding, and polishing. It is shown, however, that cold work has only a relatively small influence.

\section{EXPERIMENTAL PROCEDURE}

All specimens were annealed at $1350 \mathrm{~K}$, water quenched, heated at $1230 \mathrm{~K}$ for $1 \mathrm{hr}$, and finally water quenched again. This last heat treatment was only necessary for AISI 321 and Incoloy $800 \mathrm{H}$ in order to prevent sensitization at temperatures in the range $870-1070 \mathrm{~K}$. However, for reasons of uniformity, all samples were treated the same way. The final pretreatments used in this work were milling, electropolishing, grinding, cold rolling, and cold drawing. Except for the milled samples, all specimens were ground (220-800 grit $\mathrm{SiC}$ paper and polished on $1 \mu \mathrm{m}$ diamond powder followed by $0.05 \mu \mathrm{m} \mathrm{Al}_{2} \mathrm{O}_{3}$ powder). Samples were milled following standard procedures. All samples were ultrasonically cleaned with hexane and with ethanol for $1 \mathrm{hr}$. Oxidation tests were performed in a Stanton balance and a Cahn RG electrobalance (sensitivity 0.1 and $5 \times 10^{-3} \mathrm{mg}$, respectively). The oxidized specimens were examined by metallography, SEM/EDAX measurements, and X-ray diffraction. The chemical composition of stainless steels used are listed in Table I. Samples of AISI 314 were electropolished in an electrolyte of $80 \%$ methanol and $20 \% \mathrm{H}_{2} \mathrm{SO}_{4}(8 \mathrm{~V}$, current density $0.5 \mathrm{~A} / \mathrm{cm}^{2}$ ). Milling was carried out under continuous cooling, with a Clarckson groove cutter $(\phi=12 \mathrm{~mm})$, at $175 \mathrm{r} / \mathrm{min}$, a rate of feed of $0.05 \mathrm{~mm} / \mathrm{min}$, and a conveyor screw of $216 \mathrm{~nm} / \mathrm{min}$.

Table I. Chemical Composition of Stainless Steelss Used

\begin{tabular}{ccccccccc}
\hline Steel & $\mathrm{Cr}$ & $\mathrm{Ni}$ & $\mathrm{Ti}$ & $\mathrm{Mn}$ & $\mathrm{Si}$ & $\mathrm{C}$ & $\mathrm{S}$ & $\mathrm{Fe}$ \\
\hline AISI 304 & 17.39 & 8.88 & & 1.27 & 0.70 & 0.044 & 0.017 & bal. \\
321 & 17.45 & 10.13 & 0.40 & 1.55 & 0.52 & 0.048 & 0.003 & bal. \\
314 & 24.22 & 19.30 & & 1.29 & 2.10 & 0.06 & 0.005 & bal. \\
Incoloy 800H & 19.90 & 31.70 & 0.42 & 0.72 & 0.49 & 0.080 & 0.080 & bal. \\
\hline
\end{tabular}


The increase of the surface area by grinding, milling, etc., was determined by measuring the amount of adsorbed carbon-14 labeled species. Specimens were immersed for $0.5 \mathrm{hr}$ either in an aqueous solution of hexadecyl-1- $\mathrm{C}^{14}$-trimethylammonium bromide (HMAB 13) or in a solution of $\mathrm{C}^{14}$-stearic acid in nitrobenzene, followed by washing for $5 \mathrm{~min}$ in fresh solvent. For comparison, a worked sample was always immersed in a radioactive solution together with a electropolished one. The samples were counted under a Geiger-Müller detector tube. For further details, see refs. 13 and 14.

\section{RESULTS}

\section{Oxidation Kinetics}

In Fig. 1 the experimental results are shown for the different stainless steels used. Even at high temperatures, AISI 321 oxidizes more slowly than AISI 304 and both show a decreasing weight gain with increasing cold work (elongation). After $5-10 \mathrm{hr}$ of oxidation, however, the oxidation rate is almost the same for all deformations (elongation) applied. In Fig. 1(c) the difference in oxidation behavior for electropolished and milled samples (without surface correction) of AISI 314 is shown for two temperatures $(1318$ and $1468 \mathrm{~K})$. At both temperatures milled samples oxidize faster than

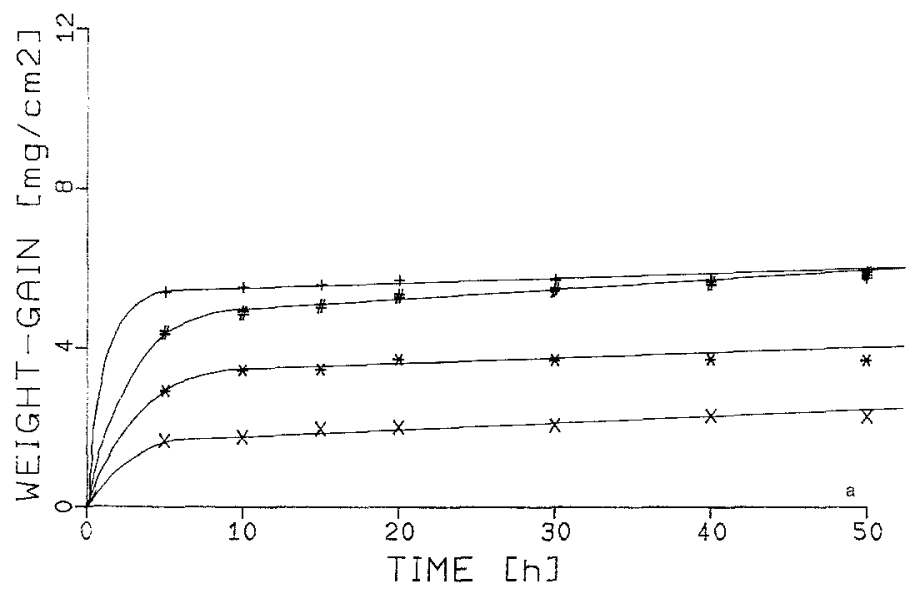

(a)

Fig. 1 (a) Typical oxidation curves for AISI 304 and AISI 321 at $T=$ $1420 \mathrm{~K}:+, 9.4 \%$ elongation; ${ }^{*}, 20 \%$ elongation; \#, milled AISI $304 ; \times$, AISI $32120 \%$ elongation. (b) Typical oxidation curves for Incoloy $800 \mathrm{H}$ at $T=1420 \mathrm{~K}: *, 6 \%$ elongation;,$+ 10 \%$ elongation; circles, $20 \%$ elongation; $\times$, milled. (c) Typical oxidation curves for AISI 314: $\bullet$, electropolished, $T=1318 \mathrm{~K} ;+$, electropolished, $T=1468 \mathrm{~K}$; filled circles, milled, $T=1318 \mathrm{~K} ; \times$, milled, $T=1468 \mathrm{~K}$. 


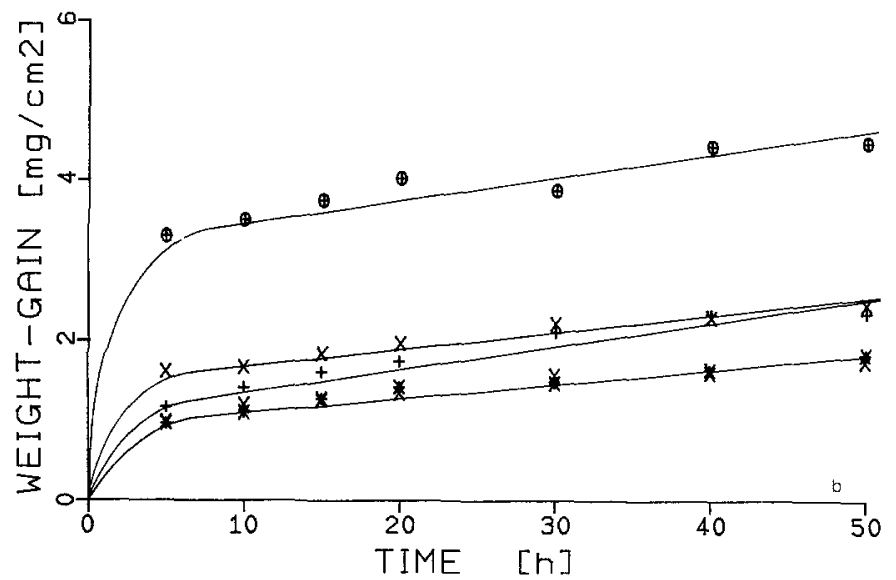

(b)

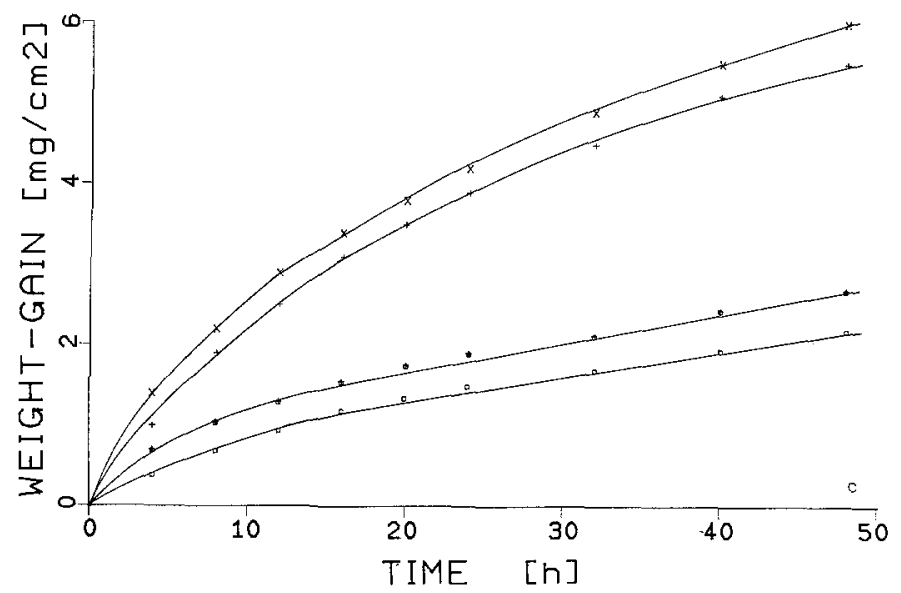

(c)

Fig. 1. Continued.

electropolished ones. Incoloy $800 \mathrm{H}$ shows an increasing weight gain with increasing cold work (elongation). The oxidation curves of milled AISI 304 and Incoloy $800 \mathrm{H}$ at various temperatures are plotted in Figs. 2(a) and (b), respectively.

After several hours of oxidation, all samples followed the parabolic rate law

$$
\left(\frac{\Delta m}{A}\right)^{2}=K_{p} t+C
$$




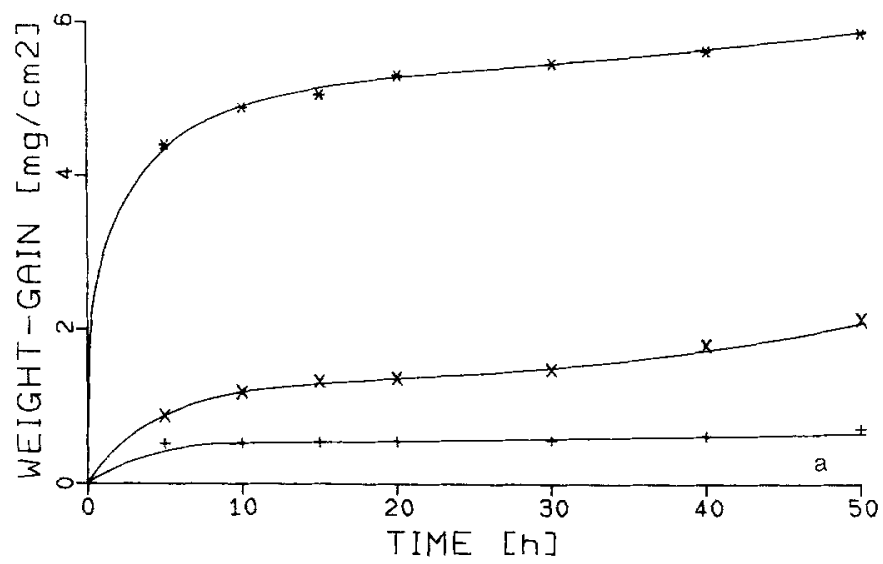

(a)

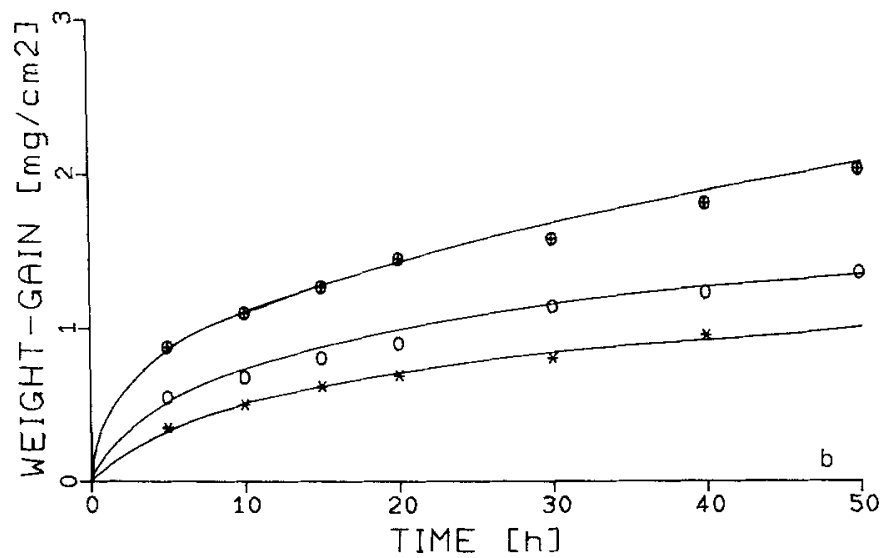

(b)

Fig. 2. (a) Milled AISI 304 at different temperatures:,$+ 1040^{\circ} \mathrm{C} ; x$, $1100^{\circ} \mathrm{C} ; *, 1150^{\circ} \mathrm{C}$. (b) Milled Incoloy $800 \mathrm{H}$ at different temperatures: *, $1035^{\circ} \mathrm{C} ; \mathrm{O}, 1100^{\circ} \mathrm{C}$; filled circles, $1150^{\circ} \mathrm{C}$.

The dependence of the parabolic rate constant, $K_{p}$, on the temperature is given by the Arrhenius equation

$$
K_{p}=K_{0} \exp \left[\frac{-E_{A}}{R T}\right]
$$

In Fig. $3, \log K_{p}$ is plotted versus the inverse of the temperature for AISI 304 and Incoloy $800 \mathrm{H}$, respectively. Table II gives some parabolic rate constants and activation energies. 
Table II. Parabolic Rate Constants and Activation Energies

\begin{tabular}{|c|c|c|c|c|}
\hline Material & Pretreatment & $T\left({ }^{\circ} \mathrm{C}\right)$ & $K_{p}\left(\mathrm{mg}^{2} / \mathrm{cm}^{4} \mathrm{~s}\right)$ & $E(\mathrm{~kJ} / \mathrm{mol})$ \\
\hline \multirow[t]{12}{*}{ AISI 304} & milled & 1070 & $1.3 \times 10^{-13} \mathrm{z}$ & \multirow{3}{*}{900} \\
\hline & & 1100 & $1.6 \times 10^{-12}$ & \\
\hline & & 1150 & $6.0 \times 10^{-10}$ & \\
\hline & polished & 880 & $\left.3.0 \times 10^{-13}\right)$ & \multirow{4}{*}{500} \\
\hline & & 950 & $1.2 \times 10^{-10}$ & \\
\hline & & 1090 & $6.0 \times 10^{-10}$ & \\
\hline & & 1100 & $4.0 \times 10^{-10}$ & \\
\hline & 320 Grit & 1070 & $5.2 \times 10^{-10}$ & \multirow{2}{*}{370} \\
\hline & & 1190 & $\left.1.8 \times 10^{-9}\right\}$ & \\
\hline & $20 \%$ elongation & 900 & $1.6 \times 10^{-13}$ & \multirow{3}{*}{280} \\
\hline & & 1000 & $\left.4.5 \times 10^{-12}\right\}$ & \\
\hline & & 1100 & $1.0 \times 10^{-11}$ & \\
\hline \multirow[t]{15}{*}{ Incoloy $800 \mathrm{H}$} & milled & 977 & $4.8 \times 10^{-12}$ & \multirow{4}{*}{115} \\
\hline & & 1035 & $7.0 \times 10^{-12}$ & \\
\hline & & 1100 & $9.0 \times 10^{-12}$ & \\
\hline & & 1150 & $1.8 \times 10^{-11}$ & \\
\hline & $20 \%$ elongation & 800 & $5.0 \times 10^{-14}$ & \multirow{3}{*}{170} \\
\hline & & 900 & $2.5 \times 10^{-13}$ & \\
\hline & & 1000 & $9.0 \times 10^{-13}$ & \\
\hline & $5 \%$ elongation & 800 & $\left.6.0 \times 10^{-14}\right)$ & \multirow{4}{*}{199} \\
\hline & & 900 & $2.0 \times 10^{-13}$ & \\
\hline & & 1000 & $2.0 \times 10^{-12}$ & \\
\hline & & 1100 & $1.3 \times 10^{-13}$ & \\
\hline & cold rolled & 800 & $3.3 \times 10^{-14}$ & \multirow{4}{*}{193} \\
\hline & & 900 & $4.3 \times 10^{-13}$ & \\
\hline & & 1000 & $\left.2.3 \times 10^{-12}\right\}$ & \\
\hline & & 1100 & $\left.7.7 \times 10^{-12}\right\}$ & \\
\hline
\end{tabular}

\section{Morphology and Analysis}

All specimens had a dark brown to black color after the oxidation experiments. The scale was porous and was always found to consist of two layers, except for the milled specimens. Figure 4 shows SEM pictures with EDAX line scans of a cross-section of AISI 321. Even at high temperatures, grain growth only occurred in the bulk of the sample, but in the layer directly below the surface $(\Sigma 10 \mu \mathrm{m})$, no grain growth was found.

$\mathrm{X}$-ray diffraction showed $\alpha-\mathrm{Fe}_{2} \mathrm{O}_{3}$ and an oxide of the form ( $\mathrm{Ni}, \mathrm{MnFe}$ ) $(\mathrm{MnFe})_{2} \mathrm{O}_{4}$ or $(\mathrm{FeCr})_{3} \mathrm{O}_{4}$ with a cubic structure and a cell constant of $0.841 \mathrm{~nm}$ to be the main constituents of the outer oxide layers. The inner oxide layer consisted of a cubic chromium oxide with a spinellike structure and a cell constant of $0.836 \mathrm{~nm}$. Figure 5 shows a typical cross-section of 


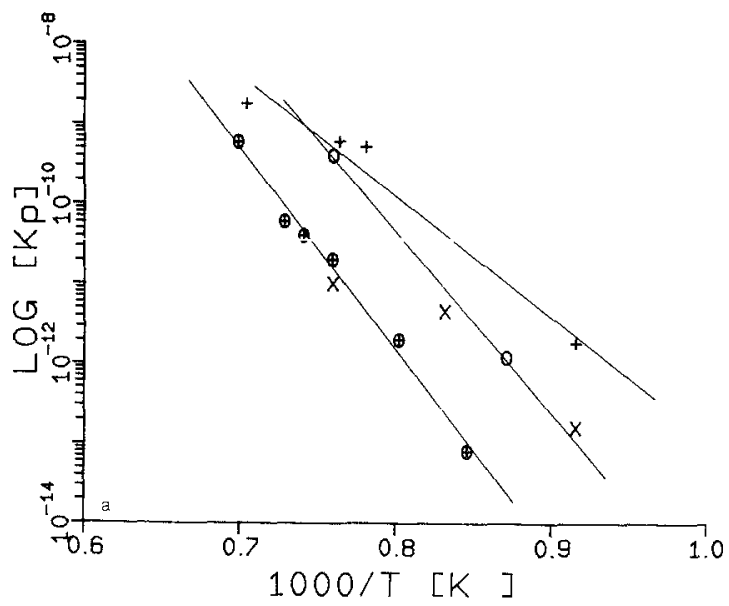

(a)

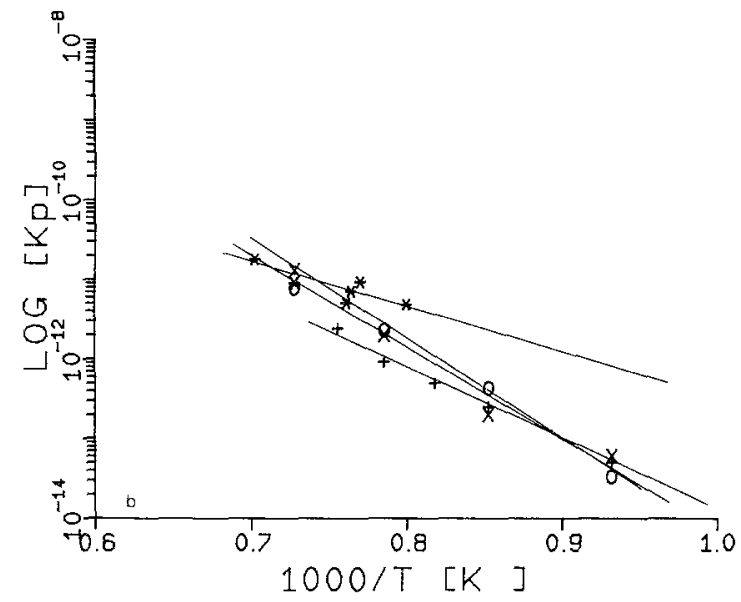

(b)

Fig. 3. (a) $\log \left[K_{p}\right]$ vs $10^{3} / T$ for AISI 304: filled circles, milled; + , coarse grained ( +320 grit); $O$, coarse grained; $\times, 20 \%$ elongation. (b) $\log \left[K_{p}\right]$ vs $10^{3} / T$ for Incoloy $800 \mathrm{H}$ : $*$, milled;,$+ 20 \%$ elongation; $O, 5 \%$ elongation; $\times$, cold rolled.

the scale on a milled sample. This consists only of chromium oxide, with some islands of iron oxide. This was observed on all milled samples oxidized below $1373 \mathrm{~K}$. Above this temperature these iron-rich oxides form a continuous layer on top of the chromium oxide layer. This change in oxidation can also be seen in the weight gain versus time curves of Fig. 2(a). 


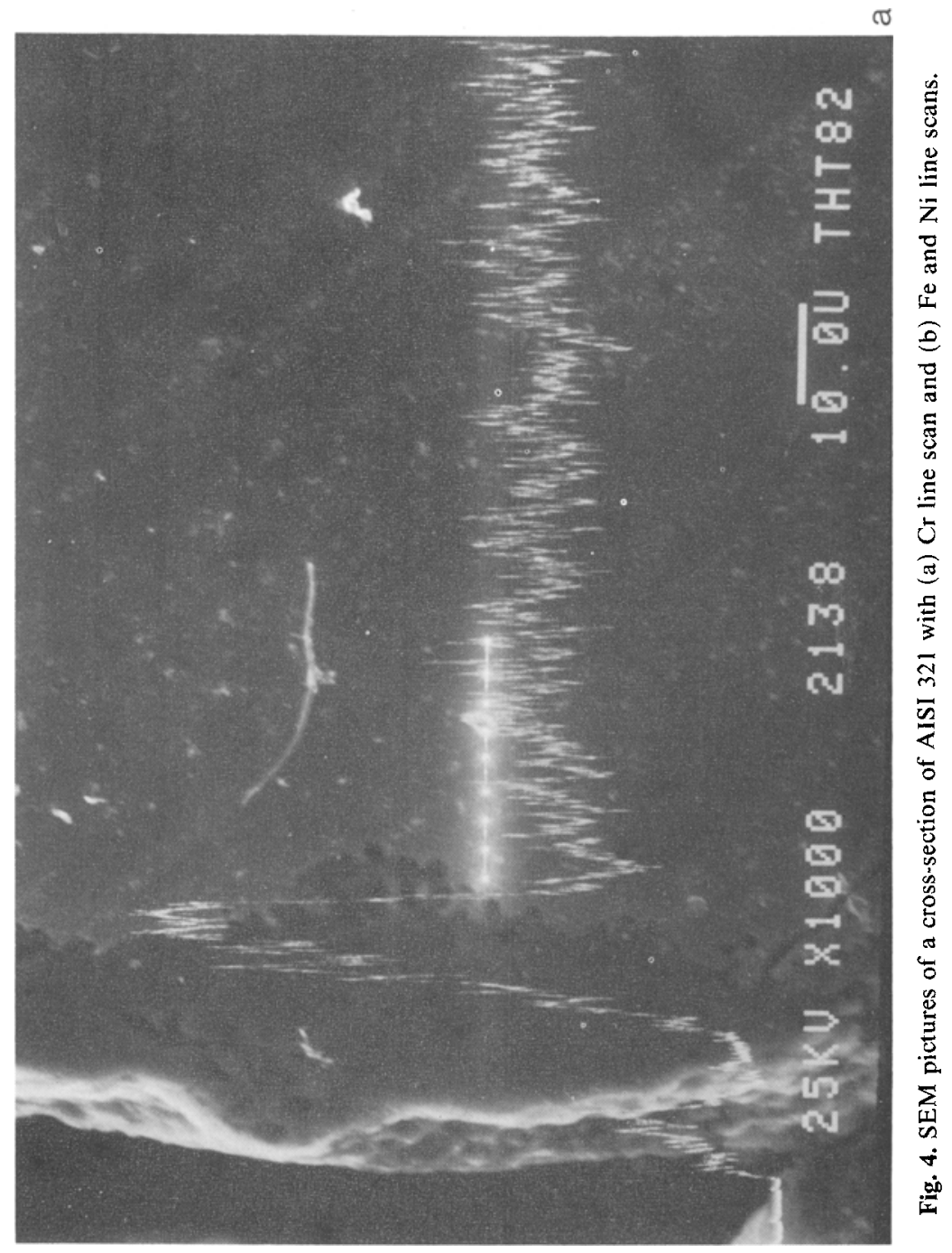


ـ

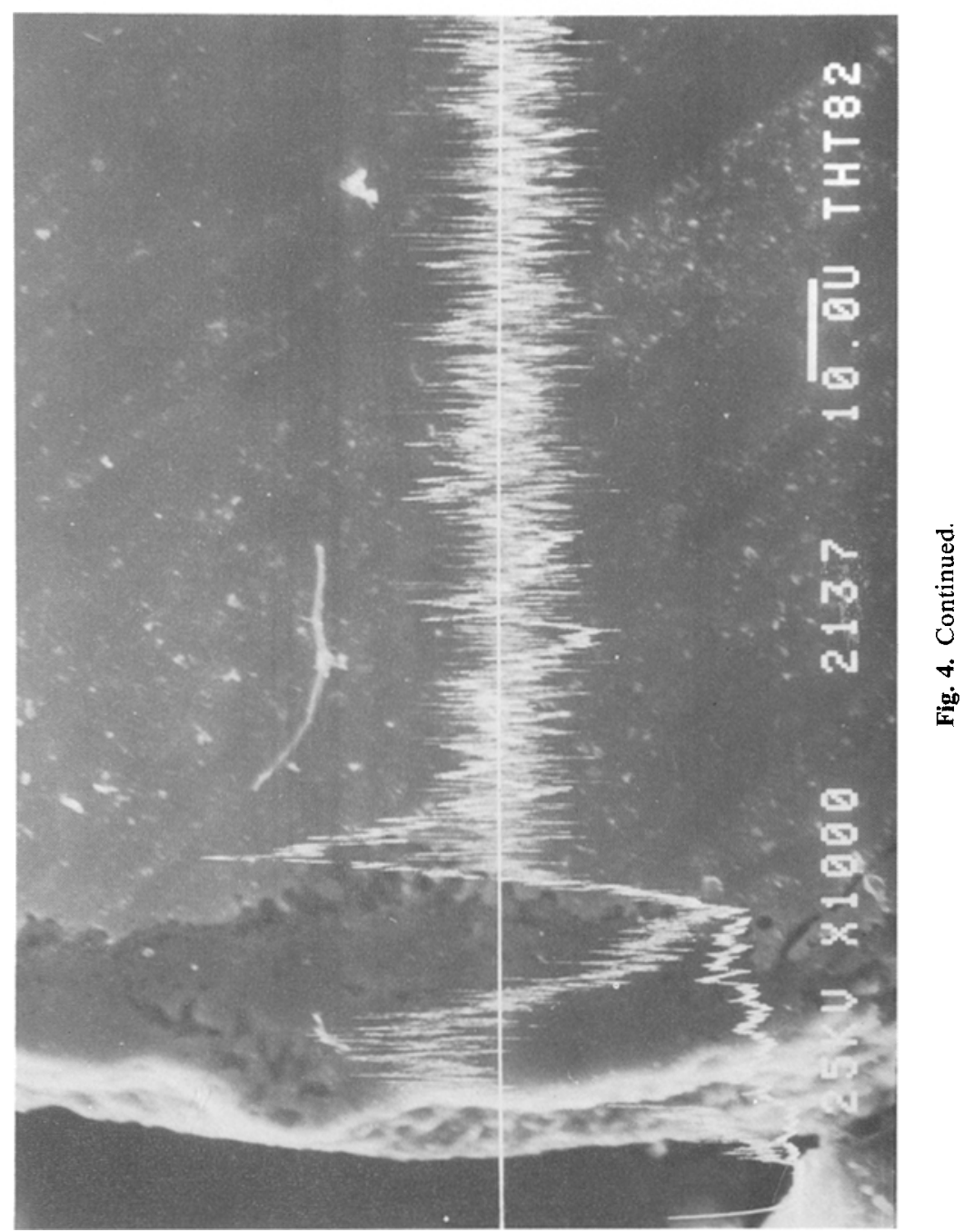




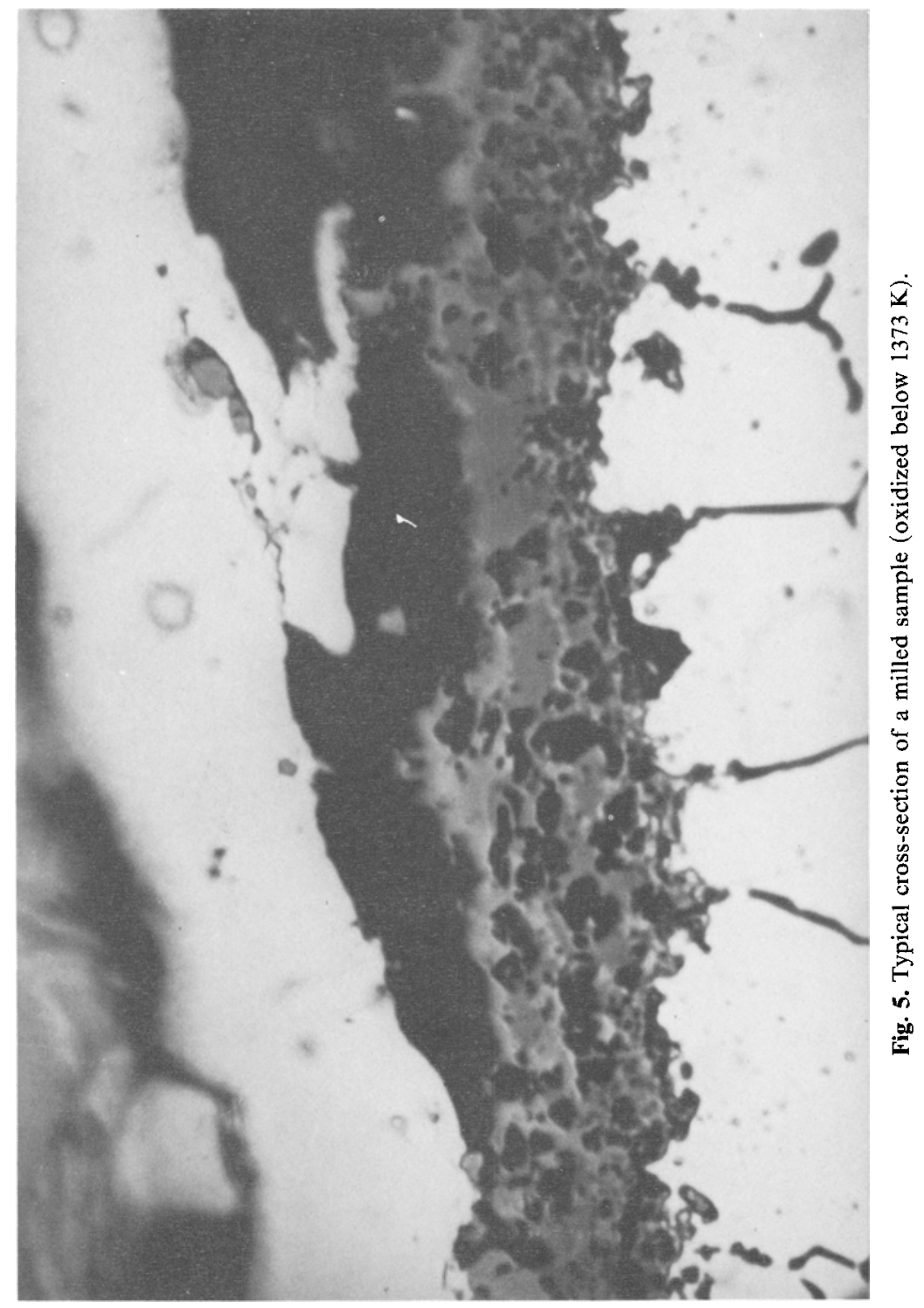




\section{Determination of the Surface Area}

Specific rates and rate constants (i.e., per unit of surface area) can of course only be determined if the real specimen surface areas are well known. Techniques utilizing the adsorption of carbon-14 or tritium labeled polar organic compounds such as HMAB and stearic acid have made possible determinations of the specific surface area of nonporous materials and flat surfaces. ${ }^{13,14}$ Both compounds were used following the method described above. This method was found to provide complete monomolecular layers.

The influence of cold work per se (i.e., without surface area enlargement) was determined by means of experiments with samples that underwent a deformation of $90 \%$ by cold rolling, followed by electropolishing. The adsorption capacity of these specimens proved to be the same as that of samples which had been electropolished, but not cold rolled. This resulted in the conclusion that working itself does not influence the specific adsorption. However, the surface area may undergo an important change due to working procedures other than cold rolling. The milled coupons, for instance, have a surface area about twice to triple that of the electropolished ones. Comparable results were found for samples ground with 320 grit $\mathrm{SiC}$ papers. It has been reported that such specimens are characterized by a roughness factor of about 2.5 . Hence, these samples show in fact a specific resistance toward oxidation which is better than that of electropolished ones (see Figs. 1 and 2).

\section{DISCUSSION}

Both AISI 304 and 321 show a decreasing oxidation rate with increasing cold work, while AISI 314 and Incoloy $800 \mathrm{H}$ show an increasing oxidation rate with increasing cold work. But as can be seen from Figs. 1-5, cold work has only a small influence on the oxidation. Cold work has a beneficial effect on the oxidation resistance of AISI 304 and 321, but in contrast with Leistikow, ${ }^{3}$ no beneficial effect has been seen on the oxidation resistance of Incoloy $800 \mathrm{H}$, even at lower temperatures $770-800 \mathrm{~K}^{6}{ }^{6}$

There are many theories for explaining the effects of pretreatment on the oxidation behavior of stainless steels. Cigada $e t$ al. $^{2}$ correlate the SCC resistance reduction to an increase in concentration of internal microstresses, generated by a reciprocal reordering of $\alpha^{\prime}$ and $\gamma$ phases. Allan and Dean ${ }^{1}$ ascribe the effect to the creation of one or more zones of differing structures and the formation of more grain boundaries as a result of recrystallization. This results in a faster diffusion of chromium just below the surface, thus yielding faster formation of a protective chromium oxide layer. 
Langevoort et al..$^{5}$ explained their results from optical microscopic measurements of AISI 304 at temperatures of $770-970 \mathrm{~K}$ with the formation of an $\alpha^{\prime}$ martensite structure within the austenite matrix. This martensite structure was found to exhibit a high rate of diffusion for chromium, ${ }^{7}$ which will lead to a very fast initial and a very slow subsequent oxidation, due to a protective $\mathrm{Cr}_{2} \mathrm{O}_{3}$ oxide layer. Even at the high temperatures used (1000$1400 \mathrm{~K}$ ), where it is expected that the importance of easy diffusion paths will be diminished, elongation still has a beneficial effect on the oxidation resistance of AISI 304 and 321. However, the effects measured are only small at the temperatures and times used in this investigation. Caplan and Cohen ${ }^{8}$ showed that below a temperature of $840 \mathrm{~K}$, cold worked Fe oxidizes faster than annealed $\mathrm{Fe}$, while at temperatures above $920 \mathrm{~K}$, cold work has no effect on the oxidation rate. They proposed that, at low temperatures, the oxide formed on cold worked $\mathrm{Fe}$ had a finer grain size than the oxide formed on annealed specimens and that the cold worked metal provided sufficient cation vacancy sinks to suppress cavity nucleation. At high temperatures, however, the results are explained by the formation of a highly defective $\mathrm{FeO}$ oxide, where lattice diffusion would not be much slower than grain boundary diffusion.

Caplan and Sproule ${ }^{9}$ reported that in the oxidation of chromium, compressive stresses, within the oxide, may play an important role. These compressive stresses are caused by cations diffusing outwards and anions inwards along grain boundaries in the oxide layer, resulting in a wrinkling of the oxide layer. Ledjeff et al. ${ }^{10}$ attribute the increase in oxidation rate of a $25 / 20$ stainless steel to a grain growth mechanism, which prevents the formation of a protective scale of $\mathrm{Cr}_{2} \mathrm{O}_{3}$ and which promotes the formation of an iron oxide scale. This is, however, in contrast with our findings, where in the surface layer (thickness $\simeq 100 \mu \mathrm{m}$ ), no grain growth was observed. Pearce and Wild ${ }^{11}$ found an increased Ti concentration (up to $23 \%$ ) in the oxide of Incoloy $800 \mathrm{H}$ after $2000 \mathrm{~min}$ of oxidation. Although (in our investigation) $\mathrm{Si}$ and some $\mathrm{Ti}$ enrichment in the oxide was found, the concentrations never exceeded a few percent.

Without surface correction, milling seems to have a negative effect on the oxidation resistance, but if the surface enlargement, due to milling, is taken into account, milling has a slight beneficial effect on the oxidation resistance. However, after $100 \mathrm{hr}$ oxidation time, this surface enlargement has largely gone, so its beneficial effect on the oxidation resistance in the long run is doubtful. It is therefore proposed that the conclusion of Allan and Dean ${ }^{1}$ that industrial treatments improve the oxidation resistance is too optimistic; however, it may be concluded that industrial treatments do no harm to the oxidation resistance of stainless steels. 


\section{CONCLUSIONS}

Due to cold work an $\alpha^{\prime}$-martensite structure is formed within the austenite matrix of AISI 304 and 321. In this martensite structure, the diffusivity of chromium is much larger than in the austenite structure, and as a consequence, the initial oxidation of cold worked 304/321 is faster until a good protective $\mathrm{Cr}_{2} \mathrm{O}_{3}$ oxide has been formed. This scale becomes more dense and adhesive with increasing cold work. Incoloy $800 \mathrm{H}$ and AISI 314, however, are more stable austenite stainless steels, and they do not show transformation of their structures into martensites as a result of cold work. Due to cold work, the concentration of defects in the metal is increased, and this will cause the presence of an increased amount of defects in the oxide layer. These defects create easy diffusion paths, resulting in a faster oxidation. Therefore, the oxidation resistance of Incoloy $800 \mathrm{H}$ decreases with increasing deformation. Cold work has an influence on the oxidation resistance, but this is only very small. In this investigation AISI 321 was observed to be oxidized more slowly than AISI 304 . This probably due to the titanium content of AISI 321. However, a separate titanium oxide layer was not observed, and only small amounts of titanium oxide were found within the oxide layer. So the role of $\mathrm{Ti}$ in the high temperature oxidation remains unclear.

\section{ACKNOWLEDGMENTS}

We thank Z. Kolar of the "Interuniversitair Reactor Instituut" Delft and M. A. de Jongh for their experimental contributions and helpful discussions.

\section{REFERENCES}

1. S. J. Allan and M. J. Dean, in Behaviour of High Temperature Alloys in Aggressive Environments I. Kirmann et al., eds., Proc. Int. Conf. Petten (The Metals Society, London, 1979), p. 139.

2. A. Cigada, N. Mazza, P. Pedeferri, G. Salvago, D. Sinigaglia, and G. Zanni, Corr. Sci. 22, 559 (1982).

3. S. Leistikow, in ref. 1, p. 197.

4. R. Stevens, Oxid. Met. 13, 71 (1979).

5. J. C. Langevoort, T. Fransen, and P. J. Gellings, Werkstoffe und Korrosion 34, 500-504 (1983).

6. G. J. Stokkers, A. van Silfhout, G. A. Bootsma, T. Fransen, and P. J. Gellings, Corr. Sci. 23, 195 (1983).

7. S. Pednekar and S. Smialowska, Corrosion 36(10), 56-577 (1980).

8. D. Caplan and M. Cohen, Corr. Sci. 6, 321 (1966). 
9. D. Caplan and G. I. Sproule, Oxid. Met. 9, 459 (1975).

10. K. Ledjeff, A. Rahmel, and M. Schorr, Oxid. Met. 15, 485 (1981).

11. R. J. Pearce and R. K. Wild, J. Nucl. Mat. 91, 156-170 (1980).

12. T. Fransen, M. A. de Jongh, and P. J. Gellings, in Proc. 8th ICMC Mainz (1981), p. 730.

13. J. Kivel, F. C. Albers, D. A. Olsen, and R. E. Johnson, J. Phys. Chem. 67, 1235 (1963).

14. C. O. Timmons, J. Colloid Interface Sci. 43, 1 (1973). 